\title{
Effect of temperature on the kinematic viscosity of biodiesel fuels
}

\author{
Zicheng Nie ${ }^{1,2, a}$, Fashe $\mathrm{Li}^{1,2, b}$, Meng Sui ${ }^{1,2, \mathrm{c}}$, Shuang Wang ${ }^{2, \mathrm{~d}}$, Gang Han ${ }^{2}$ \\ and Zuowen $\mathrm{Liu}^{2}$ \\ ${ }^{1}$ State Key Laboratory of Complex Nonferrous Metal Resources Clean Utilization, Faculty of \\ Metallurgical and Energy Engineering, Kunming University of Science and Technology, Yunnan \\ 650093, China \\ ${ }^{2}$ Faculty of Metallurgical and Energy Engineering, Kunming University of Science and Technology, \\ Yunnan 650093, China
}

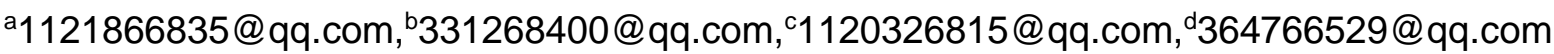

Keyword: Biodiesel; Kinematic viscosity gradient; Critical preheating temperature

\begin{abstract}
In this paper, the viscosity of different kinds of biodiesel samples was measured at $10^{\circ} \mathrm{C}$ to $80^{\circ} \mathrm{C}$. A model of kinematic viscosity estimation is proposed with very good fitting to experimental data. The optimized empirical formula has the advantages of small relative error, small error range and no obvious error fluctuation. On the basis of the optimized empirical formula, the concept of viscosity gradient of biodiesel and the concept of critical preheating temperature of biodiesel are proposed in this paper. The viscosity gradient, critical preheating temperature and application range of three kinds of biodiesel are obtained by analyzing the viscosity of different kinds of biodiesel samples.
\end{abstract}

\section{Introduction}

Biodiesel is an alternative biodegradable fuel which can be produced by aquatic plants oil such as oil crops, wild oil plants, engineered microalgae and animal fats, food waste oil and methanol through a transesterification process. Biodiesel has environmental advantages compared with petrochemical diesel [3,8].For example,biodiesel can be biodegradable, nontoxic, and environmentally friendly [5].

Kinematic viscosity not only has an impact on performance and emission characteristics of the engine, but it is one of most important properties of liquid behavior [9]. Biodiesel fuels with high viscosity tend to form larger droplets in the injection which leads to a poor fuel atomization that increases the spray tip penetration and decreases the spray angle, deriving into a poor combustion. This eventually causes the fuel injector to be coked, the piston ring adhered, and tended to form an engine deposit [2]. Biodiesel tends to precipitate waxy crystals at low temperatures, which can clog engine pipes and filters. It makes the engine difficult to start $[2,3,9]$.

Therefore, this article studies the law of kinematic viscosity of biodiesel with temperature. From these results, an optimization empirical formula of kinematic viscosity estimation is proposed with very good fitting to experimental data. Then on the basis of the optimized empirical formula, we put forward the concept of the viscosity gradient and the critical preheating temperature of biodiesel which can determine the biodiesel that is suitable for the combustion of the engine and determine the most suitable and preheating temperature. The concept proposed in this study is of helpful to the improvement of the low temperature fluidity of biodiesel.

\section{Materials and methods}

\subsection{Materials}

We used Jatropha seeds oil, rubber seeds oil and gutter oil that supplied by Yunnan Ying Ding Bioenergy Co., Ltd. (Yunnan, China) to produce biodiesel. In this study, methanol, potassium hydroxide and absolute alcohol were of about 99 purity and purchased from Merck. 


\subsection{Methods}

Three different samples of biodiesel were produced by the transesterification of Jatropha seeds oil, rubber seeds oil and gutter oil with methanol in the presence of catalysts. The kinematic viscosity of three biodiesel samples was measured following the GB/T265-1988 standard. Every experiment was replicated five times, and the temperature was maintained within $0.1{ }^{\circ} \mathrm{C}$ of the test temperature which is starting at the temperature of $10^{\circ} \mathrm{C}$ towards higher temperatures and stopped at the temperature of $80^{\circ} \mathrm{C}$. Cannon-Fenske viscosimeters were used in order to measure the kinematic viscosity of biodiesel.

\section{Results and discussion}

\subsection{The effect of temperature on the kinematic viscosity of biodiesel}

Fig. 1 shows the dependency of the measured viscosity on temperature. As the temperature is increased, the kinematic viscosity of three biodiesel samples is reduced. When the temperature is low, the kinematic viscosities of three biodiesel samples vary significantly with temperature.For example, the kinematic viscosity of biodiesel for Jatropha biodiesel, gutter oil biodiesel and rubber seed biodiesel at $20{ }^{\circ} \mathrm{C}$ was decreased by $27.5 \%, 28.0 \%$ and $25.0 \%$ respectively compared to $10{ }^{\circ} \mathrm{C}$.The kinematic viscosity of the three biodiesel samples is not very different when the temperature is high. And its kinematic viscosity changes little with the temperature. For instance, the kinematic viscosity of biodiesel from Jatropha biodiesel, gutter oil biodiesel and rubber seed biodiesel at $80^{\circ} \mathrm{C}$ was only reduced by $11.2 \%, 12.5 \%$ and $13.6 \%$ respectively compared to $70^{\circ} \mathrm{C}$. The attraction between biodiesel liquid molecules is a major factor in their kinematic viscosity.

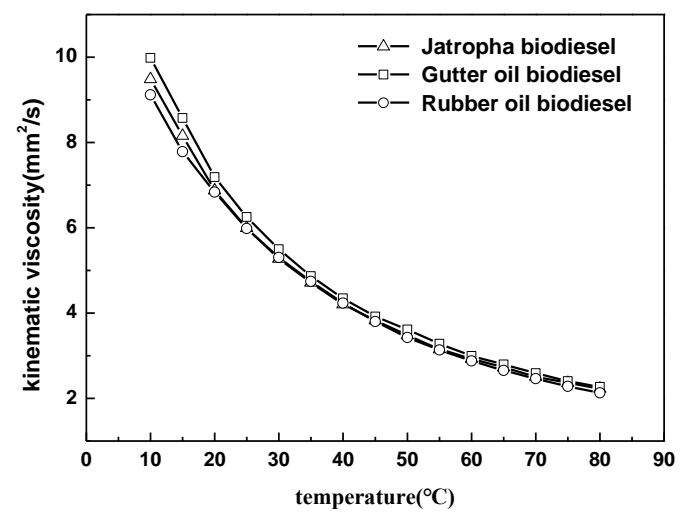

Fig.1 Dependency of the measured kinematic viscosity on temperature of three kinds of biodiesel samples.

\subsection{The empirical formula of biodiesel kinematic viscosity and temperature}

$\mathrm{S}$. Kerschbaum proposed that the viscosity is reduced in the form of an exponential equation based on the usual Arrhenius form when the temperature is over $0{ }^{\circ} \mathrm{C}$, which is the linear relationship between $\ln (\eta)$ and 1/T [5]. Eq.(1) shows the kinematic viscosity and temperature empirical formula.

$\eta=\mathrm{e}^{(\mathrm{A}+\mathrm{B} / \mathrm{T})}$.

where $\eta\left(\mathrm{mm}^{2} / \mathrm{s}\right)$ is the kinematic viscosity, $\mathrm{T}(\mathrm{K})$ is the absolute temperature, and $\mathrm{A}$ and $\mathrm{B}$ are constants specific to the biodiesel.

Results of the regressions using Eq. (1) are shown in Table 1. The calculated viscosity values and measured values for the three biodiesel samples are shown in Table 2. The empirical formula for the prediction error of Jthree biodiesel viscosity is larger at low temperature. For example, the relative errors of three kinds of biodiesel are $7.15 \%, 7.22 \%$ and $4.15 \%$ respectively at $10{ }^{\circ} \mathrm{C}$. Moreover, the error range of the empirical formula is larger and unstable, such as the error of empirical formula of gutter oil biodiesel ranges from $0.07 \%$ to $7.22 \%$. 
Table 1 The empirical formula of kinematic viscosity and temperature of three kinds of biodiesel samples.

\begin{tabular}{ccc}
\hline Samples & Empirical formula for viscosity & Correlation coefficient $\mathrm{R}^{2}$ \\
\hline Jatropha biodiesel & $\eta=\mathrm{e}^{(2050.8 / \mathrm{T}-5.071)}$ & 0.9923 \\
Gutter oil biodiesel & $\eta=\mathrm{e}^{(2096.4 / \mathrm{T}-5.182)}$ & 0.9927 \\
Rubber seed biodiesel & $\eta=\mathrm{e}^{(2068.1 / \mathrm{T}-5.140)}$ & 0.9975 \\
\hline
\end{tabular}

Table 2 Measured values of three kinds of biodiesel kinematic viscosity and calculated values of empirical formula $\left(\mathrm{mm}^{2} / \mathrm{s}\right)$.

\begin{tabular}{|c|c|c|c|c|c|c|}
\hline \multirow{2}{*}{$\begin{array}{l}\text { temperature } \\
\mathrm{t}\left({ }^{\circ} \mathrm{C}\right)\end{array}$} & \multicolumn{2}{|c|}{ Jatropha biodiesel } & \multicolumn{2}{|c|}{ Gutter oil biodiesel } & \multicolumn{2}{|c|}{ Rubber seed biodiesel } \\
\hline & $\eta$ & $\eta^{\prime}(\% \text { error })^{\mathrm{a}}$ & $\eta$ & $\eta^{\prime}(\% \text { error })^{b}$ & $\eta$ & $\eta^{\prime}(\% \text { error })^{\mathrm{c}}$ \\
\hline 10 & 9.486 & $8.808(7.15)$ & 9.981 & $9.261(7.22)$ & 9.117 & $8.739(4.15)$ \\
\hline 15 & 8.159 & $7.767(4.81)$ & 8.575 & $8.143(5.04)$ & 7.782 & $7.698(1.09)$ \\
\hline 20 & 6.878 & $6.878(0.01)$ & 7.187 & $7.192(0.07)$ & 6.836 & $6.810(0.38)$ \\
\hline 25 & 5.997 & $6.116(1.98)$ & 6.249 & $6.378(2.07)$ & 5.982 & $6.049(1.12)$ \\
\hline 30 & 5.274 & $5.459(3.51)$ & 5.496 & $5.679(3.33)$ & 5.307 & $5.395(1.65)$ \\
\hline 35 & 4.716 & $4.891(3.72)$ & 4.868 & $5.076(4.27)$ & 4.74 & $4.829(1.87)$ \\
\hline 40 & 4.203 & $4.398(4.63)$ & 4.345 & $4.553(4.78)$ & 4.234 & $4.338(2.45)$ \\
\hline 45 & 3.828 & $3.967(3.64)$ & 3.921 & $4.098(4.51)$ & 3.800 & $3.910(2.89)$ \\
\hline 50 & 3.481 & $3.590(3.14)$ & 3.612 & $3.700(2.44)$ & 3.427 & $3.535(3.16)$ \\
\hline 55 & 3.151 & $3.259(3.43)$ & 3.281 & $3.352(2.15)$ & 3.137 & $3.207(2.22)$ \\
\hline 60 & 2.928 & $2.967(1.33)$ & 2.997 & $3.045(1.60)$ & 2.877 & $2.917(1.38)$ \\
\hline 65 & 2.723 & $2.709(0.53)$ & 2.794 & $2.774(0.71)$ & 2.653 & $2.661(0.30)$ \\
\hline 70 & 2.511 & $2.479(1.26)$ & 2.590 & $2.534(2.15)$ & 2.461 & $2.434(1.11)$ \\
\hline 75 & 2.363 & $2.275(3.71)$ & 2.406 & $2.321(3.52)$ & 2.283 & $2.232(2.24)$ \\
\hline 80 & 2.229 & $2.093(6.10)$ & 2.267 & $2.131(5.98)$ & 2.126 & $2.052(3.50)$ \\
\hline
\end{tabular}

$\mathrm{a}, \mathrm{b}, \mathrm{c}$ The prediction results come from empirical formulas of the kinematic viscosity and temperature of three biodiesel respectively; $\eta$-Measured kinematic viscosity; $\eta^{\prime}$ - Calculated kinematic viscosity;

\subsection{The optimization formula of kinetic viscosity and temperature of biodiesel}

This article optimizes the empirical formula of the viscosity and temperature of biodiesel, and mainly solves the problem of relatively large and unstable prediction of kinematic viscosity when the temperature of biodiesel is low. The optimized empirical formula is shown in Eq. (2).

$$
\eta=e^{\left(A+B t+C t^{2}\right)}
$$

where $\eta(\mathrm{mm} 2 / \mathrm{s})$ is the kinematic viscosity, $\mathrm{t}\left({ }^{\circ} \mathrm{C}\right)$ is Celsius temperature, and $\mathrm{A}, \mathrm{B}$ and $\mathrm{C}$ are constants specific to the biodiesel.

Results of the regressions using Eq. (2) are shown in Table 3.With the lowest $\mathrm{R}^{2}$ value greater than 0.999, Eq. (4) provides a good fit and representation of measured values. Fig. 3, Fig. 4 and Fig. 5 respectively show the measured values, calculation values and relative errors of kinematic viscosity of Jatropha biodiesel, gutter oil biodiesel and rubber seed biodiesel.

Table 3 The optimized empirical formula f kinematic viscosity and temperature of three kinds of biodiesel samples.

\begin{tabular}{ccc}
\hline Samples & Optimized empirical formula for viscosity & Correlation coefficient $\mathrm{R}^{2}$ \\
\hline Jatropha biodiesel & $\eta=e^{\left(2.567-0.0334 t+0.000156 t^{2}\right)}$ & 0.9995 \\
Gutter oil biodiesel & $\eta=e^{\left(2.621-0.0349 t+0.000156 t^{2}\right)}$ & 0.9995 \\
Rubber seed biodiesel & $\eta=e^{\left(2.5000-0.0312 t+0.000118 t^{2}\right)}$ & 0.9999 \\
\hline
\end{tabular}



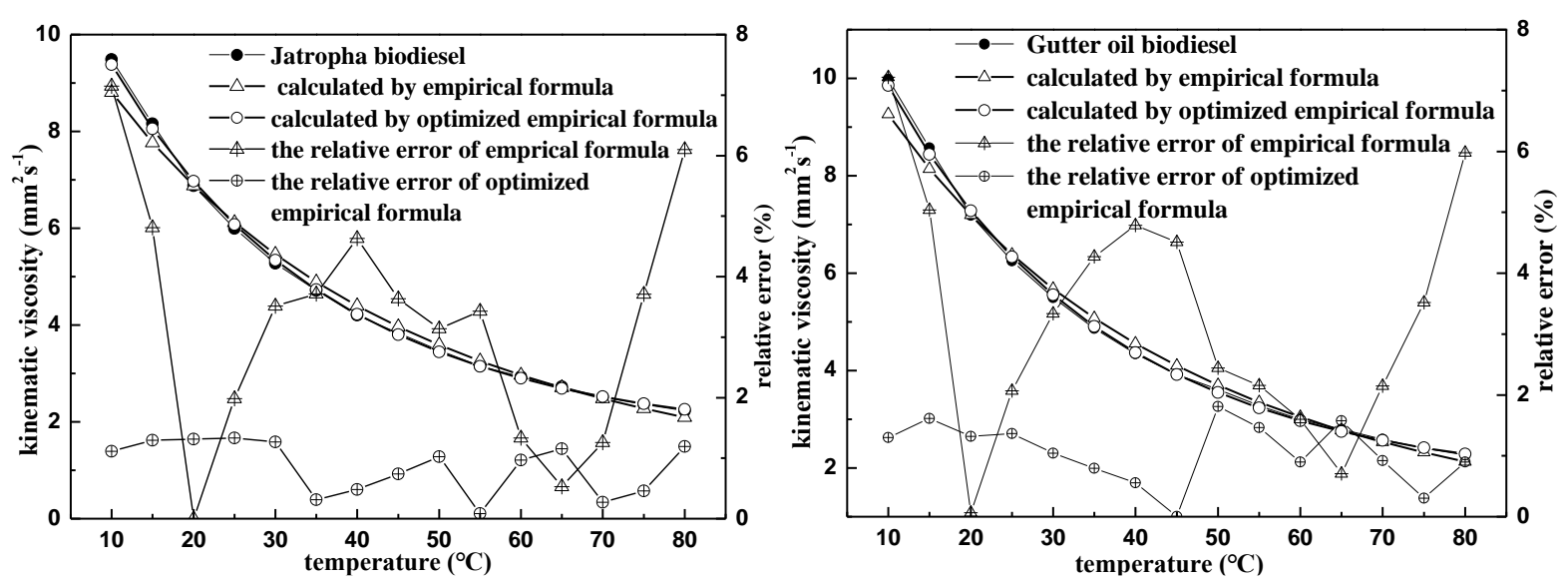

Fig. 3 Measurement and calculation of kinematic viscosity of Jatropha biodiesel and its error.
Fig. 4 Measurement and calculation of kinematic viscosity of gutter oil biodiesel and its error

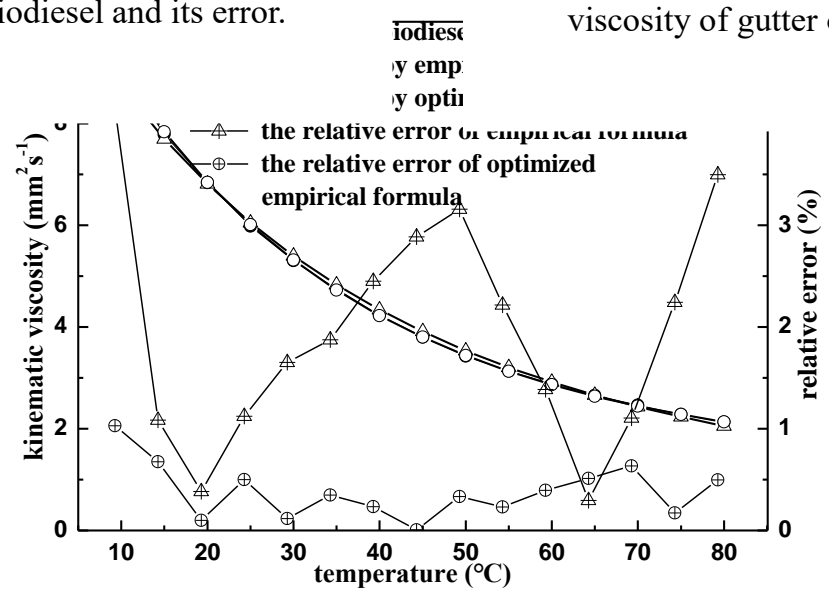

Fig. 5 Measurement and calculation of kinematic viscosity of rubber seed biodiesel and its error.

As can be seen from the figure, the error of the empirical formula is large and extremely unstable. Furthermore, from the figure it can be seen that the model of Eq. (2) fits the experimental data very satisfactorily $\left(\mathrm{R}^{2}>0.999\right)$.Compared with the empirical formula, the calculated value of the optimized empirical formula is smaller and the error is more stable. For example, the maximum relative errors of calculated values of kinematic viscosity of Jatropha biodiesel, gutter oil biodiesel and rubber seed biodiesel are $1.33 \%, 1.81 \%$ and $1.03 \%$, respectively.And the errors of calculated values of kinematic viscosity of three kinds of biodiesel are stabilized at $0.87 \%, 1.06 \%$ and $0.4 \%$. And the error of calculating the viscosity of three biodiesel is smaller when the temperature is lower. The optimized empirical formula of temperature and kinematic viscosity proposed in this paper is superior to the empirical formula in terms of correlation coefficient, accuracy and error stability.

\subsection{Analysis and research on kinematic viscosity gradient of biodiesel}

Because of the influence of temperature on the kinematic viscosity of biodiesel, especially at low temperature, the concept of kinematic viscosity gradient put forward in order to study the effect of temperature on the kinematic viscosity of biodiesel. The kinematic viscosity gradient is the change of the kinematic viscosity at unit temperature. The kinematic viscosity gradient is of great significance for the analysis and study of the low temperature fluidity and atomization of biodiesel. The expression of kinematic viscosity gradient is shown in Eq (3).

$\operatorname{grad} \eta=\left|\frac{\mathrm{d} \eta}{\mathrm{dt}}\right|$

Where $\eta(\mathrm{mm} 2 / \mathrm{s})$ is the kinematic viscosity, $t\left({ }^{\circ} \mathrm{C}\right)$ is Celsius temperature, and grad $\eta\left(\mathrm{mm} 2 \mathrm{~s}-1{ }^{\circ} \mathrm{C}^{-1}\right)$ is the kinematic viscosity gradient.

The magnitude of the viscosity gradient reflects the change rate of kinematic viscosity of 
biodiesel with temperature. When the gradient viscosity of biodiesel increases, the kinematic viscosity will decrease, and the droplet diameter decreases when atomizing, and its combustion quality and emission characteristics will be improved in the engine. The preheating cost of biodiesel will decrease when the gradient of kinematic viscosity increases. Fig. 6 is the viscosity gradient of three biodiesel. Fig. 6 shows that kinematic viscosity gradient decreases with increasing temperature. The kinematic viscosity gradient of three biodiesel samples vary significantly with temperature at low temperature. The kinematic viscosity gradient of the three biodiesel samples is not very different when the temperature is high, and its kinematic viscosity gradient changes little with the temperature.

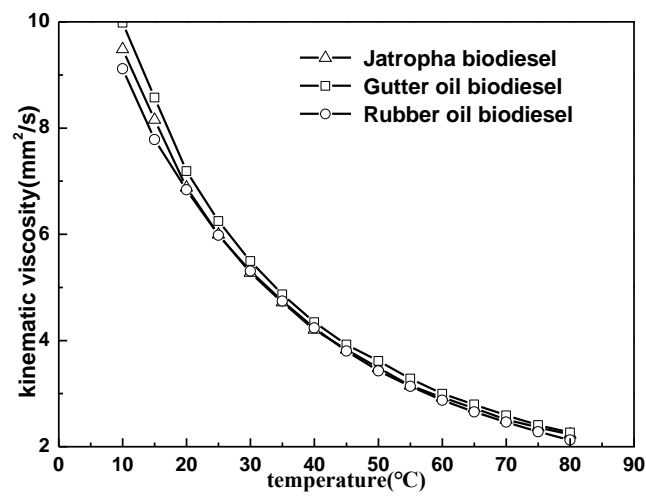

Fig. 6 Kinematic viscosity gradients of three biodiesel samples.

\section{Conclusions}

1 The kinematic viscosity of three biodiesel samples is reduced as the temperature is increased. The kinematic viscosities of three biodiesel samples vary significantly with temperature at low temperature, but it changes little at high temperature.

2 The empirical formula for the prediction error of Jatropha biodiesel, gutter oil biodiesel and rubber seed biodiesel viscosity is larger at low temperature. Moreover, the error range of the empirical formula is larger and unstable. The optimized empirical formula of temperature and kinematic viscosity proposed in this paper is superior to the empirical formula in terms of correlation coefficient, accuracy and error stability.

3 The concept of kinematic viscosity gradient is proposed in this paper which is the change of the kinematic viscosity at unit temperature. The kinematic viscosity gradient of three biodiesel samples vary significantly with temperature at low temperature, but it changes little at high temperature.

\section{Acknowledgements}

This work was financially supported by the National Natural Science Foundation of China (51766007), the Yunnan Natural Science Foundation (2015FB128), and the Yunnan Union Foundation of National Natural Science Foundation of China (U1602272).

\section{References}

[1] A.B.Chhetri,K.C.Watts. Viscosities of canola, jatropha and soapnut biodiesel at elevated temperatures and pressures.Fuel 2012;102:789-794.

[2] Magin lapuerta, Jose Rodriguez-Fernandez, David Fernandez-Rodriguez, Rayda Patino-Camino. Modeling viscosity of butanol and ethanol blends with diesel and biodiesel fuels. Fuel $2017: 199: 322-338$.

[3] E. Du, L. Cai, K. Huang, H. Tang, X. Xu, R. Tao. Reducing viscosity to promote biodiesel for energy security and improve combustion efficiency. Fuel 2018; 211:194-196.

[4] W. Yuan, A.C. Hansen, Q. Zhang. Predicting the temperature dependent viscosity of biodiesel fuels . Fuel 2009;88: 1120-1126.

[5] S Keerschbaum, G rinke. Measurement of the temperature dependent viscosity of biodiesel 
fuels. Fuel 2004;83: 287-291.

[6] J. Corach, M. Colman, P.A. Sorichetti, S.D. Romano. Kinematic viscosity of soybean biodiesel and diesel fossil fuel blends: Estimation from permittivity and temperature. Fuel 2017;207: 488-492.

[7] Tat ME, Van Gerpen JH, The kinematic viscosity of biodiesel and its blends with diesel. Fuel 1999; 76(12):1511-3.

[8] Gülüm M. Experimental investigation of the effect of various production parameters on the some fuel properties of produced biodiesels from corn and hazelnut oils Master's Thesis. Trabzon, TURKEY: Department of Mechanical Engineering, Karadeniz Technical University; 2014.

[9] R.E. Tate, K.C. Watts, C.A.W. Allen, K.I. Wilkie. The viscosities of three biodiesel fuels at temperatures up to $300{ }^{\circ} \mathrm{C}$. Fuel 2006;85: 1010-1015.

[10] Pirault JA, Klippenstein SJ. J Phys Chem A 2006;110:10528-44

[11] Allen CAW, Watts KC, Ackman RG, Pegg MJ. Predicting the viscosity of biodiesel fuels from their fatty acid ester composition. Fuel 1999;78: 1319-26.

[12] Luis Felipe Ramirez-Vreduzco, Blanca Estela Garcia-Flores, Javier Esteban Rodriguez-Rodriguez, Alicia del Rayo Jaramillo-Jacob. Prediction of the density and viscosity in biodiesel blends at various temperatures. Fuel 2011;90: 1751-1761.

[13] Kanit Krisnangkura, Chanida Sansa-ard, Kornkanok Aryusuk, Supathra Lilitchan, Kanisa Kittiratanapiboon. An empirical approach for prediting kinematic viscosities of biodiesel blends. Fuel 2010;89: 2775-2780.

[14] Sibel Geacai, Olga lulian, Irina Nita. Measurement, correlation and prediction of biodiesel blends viscosity. Fuel 2015;143: 268-274. 